\title{
BIOÉTICA Y EL ISLAM
}

\section{Rodrigo Karmy Bolton*}

Resumen: El presente artículo plantea la perspectiva del Islam respecto de la vida. No se aborda al Islam como una religión "ilustrada" y vanguardia de la historia "racional" europea ni, en su defecto, como un "atentado" a los valores liberales de la tolerancia y la democracia contemporáneas. Más bien, se lo considera en relación con la bioética, en la cual la interrogación sobre el problema de la técnica resulta fundamental. Interesa situar al Islam como una específica "antropotecnia”, esto es, como un conjunto de dispositivos que hacen posible el "devenir hombre del animal humano". Una perspectiva "antropotécnica" significa preguntarse por los dispositivos que, en el Islam, hacen posible el gobierno de los hombres.

Palabras clave: vida, Islam, antropotecnia, bioética

\section{BIOETHICS AND ISLAM}

\begin{abstract}
This article brings up Islam perspective towards life. Islam is not presented as an "illustrated" religion and vanguard of European "rational" history, nor, by defect, as an "assault" towards the contemporary liberal values of tolerance and democracy. Rather, it is considered in relation to bioethics, in which the questioni ng about the problem of technology is fundamental. Is it of interest to situate Islam as a specific "anthropotechnia", that is as a gathering of forces that makes possible the "transformation of human animal into man". An "anthropotecnia" perspective means to reflect in the forces which, in Islam, make possible human governing.
\end{abstract}

Key words: life, Islam, anthropotecnia, bioethics

\section{BIOÉTICA E O ISLÃ}

Resumo: O presente artigo propóe a perspectiva do Islã a respeito da vida. Não se aborda o Islã como uma religião "ilustrada" e vanguarda da história "racional" europeia, nem, em seu defeito, como um "atentado" aos valores liberais da tolerância e a democracia contemporâneas. Melhor, ele é considerado em relação com a bioética, na qual a interrogação sobre o problema da técnica resulta fundamental. Interessa situar o Islá como uma específica "antropotecnia", isto é, como um conjunto de dispositivos que fazem possível o "devenir homem do animal humano". Uma perspectiva "antropotécnica” significa perguntarse pelos dispositivos que no Islã torna possível o governo dos homens.

Palavras-chave: vida, Islã, antropotecnia, bioética

* Doctor (๐) en Filosofía. Centro de Estudios Árabes, Universidad de Chile, Chile Correspondencia: rkarmy@gmail.com 


\section{Introducción}

La pregunta sobre la antropotecnia supone rastrear algunas discusiones teológicas fundamentales, porque en el mundo medieval la teología estuvo lejos de ser una disciplina como cualquier otra. Al contrario, fue siempre el dispositivo que catalizó la institucionalización de los diversos modos de gobierno. A esta luz habría que leer las discusiones sobre el estatuto de la providencia, sobre la voluntad de Dios, sobre la creación, sobre el problema del "mal", la justicia, etc. Y a su vez habrá que interrogarse por esas formas teológicas que dieron lugar y no dejan de dar lugar hoy día a la modernidad. Es decir, se trata de ver no la "causa" teológica (judía, cristiana o islámica) en la modernidad, sino cómo la propia modernidad deja entrever su propio archéin teológico. La providencia no es una mera "causa", sino un origen que no deja de actuar en el presente. Piénsese solamente en el dispositivo de la confesión, cuya genealogía remite a las formas pastorales del cristianismo monástico, según los trabajos de Michel Foucault.

Es natural ceñirse al esquema prefabricado que se propone hoy, instalando al Islam en el Oriente de un determinado Occidente. De este modo, se presupone la separación previa entre Oriente y Occidente como dos entidades, sino contrapuestas, al menos diferentes entre sí. Esta separación da lugar en el periodismo actual a dos tesis inversas pero igualmente cómplices. Por un lado, la tesis del "choque de civilizaciones", según la cual después de la caída de todo referente ideológico habrían quedado las civilizaciones desnudas que comienzan a conflictuar entre sí. Por otro, la tesis del "diálogo de civilizaciones", según la cual es necesario aunar las diferentes civilizaciones en una misma "mesa de diálogo" para facilitar su mutua comprensión.

Con el fin de evitar situarnos en contra o a favor de este "cliché" civilizacional que impone el periodismo actual, quisiera abrir otro lugar desde el cual pensar el problema. Este lugar, este terreno común, es el monoteísmo, que se sitúa como el horizonte antropotécnico sobre el cual se levanta el judaísmo, el cristianismo y el islam, las tres religiones de raíz abrahámica.

Ahora bien, el monoteísmo se sitúa desde el principio a la luz de una paradoja. Dice Jean-Luc Nancy: "Lo enuncio así: el monoteísmo es en realidad el ateísmo"(1). ¿Cómo el monoteísmo puede ser pensado como un ateísmo y, por tanto, cómo el nihilismo occidental puede ser pensado como la deriva más propia del monoteísmo?
Todo monoteísmo se caracteriza no solamente por reducir la multiplicidad de los dioses a la unidad del único Dios, sino también por el hecho de que Dios se ha retirado del mundo y ha dejado a los hombres a su haber. El monoteísmo - a diferencia del politeísmo- supone una separación ontológica entre Dios y el mundo, entre la divinidad y la humanidad. Es lo que los teólogos llaman diástasis, esto es, el hiato, la abertura entre Dios y el hombre. A esta luz, el monoteísmo implica, en su propia consistencia, un movimiento paradojal: por un lado, subjetiva a los hombres en la unicidad absoluta de Dios y, por otro, los abandona a su haber en el desierto que es el mundo. Dios abandona a los hombres y los insta a apropiarse del mundo. Este último es el elemento ateológico que lleva todo monoteísmo, del cual las tres derivas -la judía, la islámica y la cristianase habrían hecho cargo de modos diferentes.

Así, el monoteísmo es, en una perspectiva históricofilosófica, el ateísmo y, por ello, la estructura de Occidente, el nudo antropotécnico desde el cual provenimos. Veamos a continuación algunas cuestiones de orden general para, desde aquí, acercarnos al problema de la vida en el Islam.

\section{El Islam como restitución del monoteísmo}

En árabe islam significa "sometimiento" y muslim "el que se somete". Ese sometimiento a Dios es para el Islam lo decisivo, el sometimiento a la abertura de Dios que tensiona, que abisma, que conmueve. Si se pone atención, la palabra islam y muslim comparten una misma estructura consonante. Y, como sucede en árabe, todas las palabras que comparten una estructura consonante comparten a su vez un mismo campo semántico. Así pues islam y muslim llevan consigo la raíz consonante $s i m$, de la cual se compone la palabra de raíz hebrea salam que significa paz. Islam, muslim y salam configuran una sola constelación que tiene lugar en la revelación coránica. En dicha constelación el hombre se sitúa frente a lo Abierto, frente a la invisible presencia de Dios: esa abertura ontológica que expone al hombre a lo radicalmente otro. El hombre ex-puesto, es decir, situado fuera de sí, orientado totalmente a Dios. Es eso lo que define al muslim y lo que designa islam. Sólo hay paz (salam) en la medida en que el muslim tiene una fe (shahada) en Dios, es decir, en la medida en que este se define por su ser totalmente expuesto.

La abertura es un elemento constitutivo del Islam. Tanto así que la primera Sura del Corán es llamada al-fatiha, que significa "la que abre" (2). Abre al hombre a la Pa- 
labra de Dios. Esa abertura, esa fatiha, es pues lo que define a la revelación. Porque, desde el punto de vista del Islam, esa revelación constituye el acontecimiento originario por el cual la Palabra de Dios -que es palabra creadora- se comunica por última vez a los hombres.

Ahora bien, lo que Dios revela a los hombres es la sharia o ley islámica, que va a regir toda la vida de la comunidad (umma) musulmana. La ley viene a dar contenido al abismo de la revelación de Dios. Por ello, la invisibilidad de Dios se visibiliza en la forma de la ley islámica que Dios da a los hombres. Pero este "hacerse-visible" no tiene la forma de la encarnación cristiana, porque para los musulmanes la revelación de la sharia o ley islámica es, al mismo tiempo, un acto de presencia y de ausencia de Dios. Este, manteniéndose en una trascendencia absoluta, jamás entra en la Historia de los hombres, ya que nunca se convierte en la Historia misma de los hombres. Para el Islam, de hecho, esta no existe como un proceso universal que avanza en una línea determinada, porque la Historia, tal como aparece en las filosofías de la historia decimonónicas, no es otra cosa que la figura secularizada de la encarnación de Dios en la tierra. Para el Islam, en cambio, la Historia es la historia de la revelación que va desde Adán hasta Mahoma o, inclusive, como en el caso de los shiítas, más allá, inaugurando diferentes ciclos proféticos. La revelación islámica tiene lugar sólo donde Dios se retira de aquello que él mismo ha revelado, sólo donde Dios mantiene su trascendencia absoluta respecto del mundo.

Para el Islam la revelación no acontece, como en el cristianismo, en la forma de un Hijo de Dios (un encarnado), sino en la forma de un enviado (rasul). Para el Islam existen Profetas (nabi) y Enviados (rasul). Los primeros exhortan y advierten (responden a la figura veterotestamentaria de los profetas); los segundos, en cambio, no sólo exhortan y advierten, sino que además constituyen un escrito en el cual consignan las revelaciones divinas(3). En este último caso, Abraham, Moisés y Jesucristo constituyen los tres grandes Enviados, a los cuales se agrega un cuarto, que es Mahoma.

La operación teológica del Islam no hace otra cosa que "reescribir" la historia de la revelación, retornando a Abraham antes que a Moisés o a Jesús. ¿̨Por qué? Porque el centro de la polémica lo constituye la fisura producida en el seno del monoteísmo entre judíos y cristianos. Recuérdese que, desde un punto de vista histórico, previo al surgimiento del Islam comunidades judeocristianas habitaban en la península arábiga, las cuales, si bien reco- nocían a Jesús, no lo asumían como Hijo de Dios(4). Asimismo, desde los primeros concilios de la Iglesia cristiana se produce un frecuente exilio de los docetas, los arrianos y otros, quienes, acusados de subsumir la figura del Hijo en la del Padre, llegaron bajo el cargo de "herejía". Por ello, la polémica del Islam se dirige contra judíos y cristianos, pero no porque estos sean “infieles", sino porque, siendo de la misma raíz abrahámica, han errado el camino: los primeros porque no reconocieron a Jesús como profeta $y$ los segundos porque derivaron en una teología trinitaria, perdiendo así la unicidad de Alláh.

El Corán dice sobre los judíos: "Dimos a Moisés la Escritura y mandamos Enviados después de él. Dimos a Jesús, hijo de María, las pruebas claras y le fortalecimos con el Espíritu Santo. ¿Es que teníais que mostraros altivos siempre que venía a vosotros un Enviado con algo que no deseabais? A unos les desmentiste, a otros les disteis muerte" (S, 2, 87). El Corán condena a los judíos por la incredulidad que estos mostraron respecto de los Enviados de Dios, ya sea con Moisés (que desmintieron) o Jesús (que le condenaron a muerte).

Y contra los cristianos se lee: "¡Gente de la escritura! No exageréis en vuestra religión! ¡No digáis de Dios sino la verdad: que el Ungido, Jesús, hijo de María, es solamente el Enviado de Dios y su Palabra, que El ha comunicado a María, y un espíritu que procede de Él! ¡Creed, pues, en Dios y en sus enviados! ¡No digáis Tres! ¡Basta ya, será mejor para vosotros! Dios es sólo un Dios Uno. ¡Gloria a Él! (...) Tener un hijo (...) Suyo es lo que está en los cielos y en la Tierra (...) ¡Dios basta como protector!" $(S, 4,171)$.

Es decir, para el Corán la deriva trinitaria del cristianismo aleja a los hombres de la unicidad de Dios, que sitúa a Jesús como un Enviado más para convertirlo en el Hijo de Dios, es decir, para situarlo como el Verbo encarnado. Pero esto no significa que para el Corán judíos y cristianos tengan el estatuto de "infieles", sino que ambos, por el solo hecho de creer en Dios y pertenecer por tanto al linaje abrahámico, pueden entrar en el jardín del Edén. Es por ello que ni los judíos ni los cristianos son tratados como los "asociadores" ni como los incrédulos en general.

De ahí la operación coránica de volver a la figura de Abraham para situarlo como un hanif, es decir, como aquel que, no siendo ni judío ni cristiano, es sometido a Dios: "Dicen: Si sois judíos o cristianos, estáis en la vía recta". Di: "No, antes bien la religión de Abraham, que fue hanif y no asociador / Decid: "Creemos en 
Dios y en lo que se nos ha revelado, en lo que reveló a Abraham, Ismael, Isaac, Jacob y las tribus, en lo que Moisés, Jesús y los profetas recibieron de su Señor. No hacemos distinción entre ninguno de ellos y nos sometemos a Él” (S, 2, 135-136).

Estas dos aleyas de la Sura 2 muestran muy bien la operación que pretende realizar el Islam, a saber, unificar la fractura del monoteísmo y situarse como la conciliación de ambos movimientos. Por ello el Corán no deja de recordar: “¡Dios! No hay más dios que Él, el Viviente, el Subsistente / Él te ha revelado la Escritura con la Verdad, en confirmación con los mensajes anteriores. Él ha revelado la Torá y el Evangelio (...) No hay más Dios que Él, el Poderoso el Sabio" (S, 3, 2-3-6). La frase que se repite insistentemente - "no hay más Dios que Él"- es la frase que restituye al monoteísmo de su fractura. Un mismo Dios ha revelado la Torá, el Evangelio y el Corán, lo que tiene su equivalente en las figuras de Moisés, Jesús y Mahoma. Este último, siendo la "confirmación de los mensajes anteriores", se presenta como la restitución del monoteísmo, suturando -o al menos intentando suturar- la fractura entre judíos y cristianos.

Es importante considerar que la revelación de la Palabra de Dios - porque el Corán es sólo Palabra de Dios, no Palabra humana como en el cristianismo- se constituye como lo que en nuestro tiempo llamamos un "doble vínculo". Porque la revelación, en cuanto acontecimiento, tiene dos caras. Por un lado, tiene una dimensión exotérica (zahir), es decir, "manifiesta" o "aparente", si se quiere, que define a la ley (sharia) que se presenta ante los ojos de los hombres. Por otro, una dimensión esotérica (batin), "oculta", "misteriosa", que define a la abertura infinita que Dios representa para los hombres. La dimensión exotérica trae a presencia ciertas cosas, por ejemplo la ley (sharia); la esotérica, en cambio, enfatiza no en la ley sino en la verdad (haqiqat).

Este doble vínculo que estructura a la revelación tendrá consecuencias decisivas en el devenir del propio Islam, del cual se desprenderán al menos dos vías que, por cierto, no serán las únicas y que surgen en los primeros tiempos del Islam, a partir de la disputa por la sucesión de Mahoma entre Abu Bakr (que sería el primer halifa o "sucesor" del profeta) y Alí (hijo de Fátima y nieto de Mahoma). En primer lugar, surge el Islam sunnita (ortodoxo), a partir del apoyo al primero, y, en segundo, el Islam shiíta, que sigue a Alí (de ahí su nombre "shiítas" que significa "seguidores" o "partisanos"). El común acuerdo entre ambos es que Mahoma constituye el "sello de los profetas", a través del cual se ha revelado la ley (sharia). Sin embargo, si para los sunnitas todo el ciclo profético termina en Mahoma, con la consecuencia de que la fe se identifica al cumplimiento de la ley(5), para los shiítas, en cambio, Mahoma constituye la última revelación de carácter exotérico, pero el inicio al ciclo esotérico de la profecía: el personaje decisivo ya no es el profeta, como para los sunnís, sino el Imam (guía espiritual).

De esta manera, para los shiítas la fe no se identifica con la ley, sino con la dimensión esotérica que espera al último Imam, el Mahdi. Esto es importante porque, si el efecto de identificar la fe con la ley es la legitimación de toda autoridad y la institucionalización del Islam sunnita como una "religión de Estado", entonces el Islam shiíta no clausuró toda la historia de la revelación profética de Mahoma, sino que, con ella, reinició un nuevo ciclo profético que asume un elemento mesiánico decisivo, a saber, la espera del último Imam.

Según Henry Corbin, los elementos gnósticos y mesiánicos presentes en el cristianismo primitivo y que una vez instituida la Iglesia fueron reprimidos vuelven a aparecer en el seno del Islam y, en particular, en el Islam shiíta, que instituye una ética de la resurrección a través de la gnosis (conocimiento salvífico de las almas, denominado " $t a$ ' wil"). Lejos de restituir el monoteísmo entre el judaísmo y el cristianismo, el devenir del Islam no hizo sino profundizar en su fractura, extendiendo el éxodo de los hombres: por un lado, en el Islam sunnita que se centra en la ley y, por otro, en el islam shiíta que se centra en lo por venir (la figura del último Imam), hasta el punto de poder abrogar la ley(6).

Si bien el Islam prometió la restitución del proyecto antropotécnico monoteísta, nunca lo pudo cumplir del todo, pues este proyecto encuentra en la forma del Islam una nueva y más profunda fractura que correrá en paralelo con la vía que propondrá el cristianismo. Bástenos por ahora dar un panorama general del Islam, de sus polémicas externas (judaísmo y cristianismo) y de sus polémicas internas (sunna-shia) para, a continuación, centrarnos en el problema de la creación y la resurrección de la vida.

\section{Vida en el Islam}

En árabe existen dos términos para designar lo que en las lenguas latinas designamos sólo con uno, a saber, la "vida". Por un lado, $a h$ ' ya, que se refiere a todo el vivir, a los seres vivos, a lo fértil, lo animado, al organismo, etc.; por otro, aish, que designa más bien la vida en su 
dimensión cualitativa, allí donde el hombre habita el mundo. En el Corán se utiliza generalmente la palabra ah' ya, de la cual se deriva la palabra de "resurrección" ih 'ya o el "vivificador" como atributo decisivo de Dios (mu'yaq). Quizás, a modo de hipótesis, podríamos decir que la palabra "vida" utilizada en el Corán, con todas sus derivaciones, es el análogo del griego zoé usado en el Evangelio. Es necesario confirmar si podemos hacer esta analogía y, sobre todo, verificar si $a h^{\prime}$ ya es la traducción y resignificación árabe del griego zoé.

A esta luz, habrá que preguntar si esta vida, en tanto donación de Dios, tiene la forma de una receptividad absoluta que, por serlo, se revela como aquello que está siempre fuera-de-lugar, en la medida en que está siempre frente a lo Abierto. Es posible que ese fuerade-lugar radical que constituye a lo viviente salga a la luz en los elementos mesiánicos del Islam shiíta, el cual, en su espera, desactiva la dimensión exotérica de la Ley, restitución del proyecto antropotécnico del monoteísmo pero, a la vez, ruptura incesante en su propio interior de ese elemento "Abierto" que el monoteísmo inaugura en la antropotecnia de los hombres.

No obstante el Islam captura a la vida humana en la forma de la Ley, esta última nunca puede suturar la totalidad del espacio de lo viviente. En esa medida, aunque el Islam se presenta como la restitución del monoteísmo, no constituye sino parte de su deriva desintegradora, cuya vía alternativa se habría desplegado paralelamente con el cristianismo.

\section{La teo-zoo-logía contemporánea}

Es sintomático que desde la Revolución Francesa las ciencias sociales y la filosofía no hayan dejado de pensar al mismo tiempo sobre la religión y la vida. Pareciera como si el nudo que se forma entre religión y vida pudiera decirnos algo sobre nuestra proveniencia. Al menos, es lo que se puede advertir en Nietzsche y, me atrevería a decir, en toda la filosofía del siglo XX. El mismo Foucault, cuando desarrolla su genealogía de la biopolítica moderna, no puede dejar de tocar al poder pastoral cristiano.

La teo-zoo-logía -para utilizar el neologismo con el que Jacob Taubes caracterizaba a la ideología nazi- parece constituir el nudo sobre el cual gira el proyecto antropotécnico del monoteísmo (a la vez, griego-musulmánhebreo y cristiano), ya que sólo en la modernidad de su despliegue planetario parece salir a la luz el núcleo radicalmente aporético que le constituye (lo Abierto que estaría en el Islam). Esta situación, sin embargo, abre una vía para comenzar a pensar cómo el proyecto antropotécnico del monoteísmo pasó de la humanización de la animalidad del hombre a la animalización de la humanidad del hombre(7)'.

Así, pues, lo que Michel Foucault llamó "biopolítica", y que designa el conjunto de mecanismos por los cuales se ha hecho posible el ingreso decisivo de la vida natural a los cálculos explícitos del poder, no sólo tendría una raíz cristiana, sino, sobre todo, pertenecería a la constelación más amplia circunscrita al proyecto antropotécnico del monoteísmo que, como hemos visto, incluye al Islam. Por ello, el nudo teo-zoo-lógico es todavía un problema que aquí solamente podemos plantear, pero que emerge cuando los diversos discursos teológicos contemporáneos -a saber, el cristiano, el judío o el musulmán- son obligados a pronunciarse acerca de determinados problemas éticos que la deriva biopolítica moderna nos plantea. Y esto conjuntamente con el movimiento por el cual las tres religiones, y en este caso el Islam, han sufrido a su vez una "biopolitización”, es decir, han debido fundamentar y prescribir teológicamente la nueva realidad biomédica.

Este proceso es extrańo, porque si es cierto que el biopoder se debe a una matriz antropotécnica, sostenida en parte por el monoteísmo, entonces las derivas históricas de este -a saber, el cristianismo, el judaísmo y el Islam- se consuman en la forma de una biopolítica y, a su vez, el biopoder revela su propio archéin teológico, instituyendo así un círculo entre la esfera teológicojurídica y la biomédica, recordando, por cierto, que la teología fue siempre la forma más antigua de la política. ¿Qué es la antropotecnia si no ese círculo entre teología y biología, entre Dios y los vivientes, entre la divinidad y la animalidad, que en nuestro tiempo se despliega planetariamente en la forma de un biopoder?

Por tanto, la emergencia planetaria del biopoder, con todos los nuevos problemas éticos que ha planteado a la práctica científica, ha obligado también al Islam a tomar una posición.

A continuación quisiera referirme brevemente a lo que actualmente plantean algunas fatwas islámicas respecto del aborto y la ingeniería genética, respectivamente. En

1 Agamben escribe: "Y no somos sólo, por emplear las palabras de Foucault, animales en cuya política está puesta en entredicho su vida de seres vivientes, sino también, a la inversa, ciudadanos en cuyo cuerpo natural está puesto en entredicho su propia vida política”. 
todo caso, hay que considerar que estas opiniones varían absolutamente entre los juristas islámicos. No existe una posición oficial precisamente porque en el Islam no existe una autoridad pontificia que establezca dogmas. Sin embargo, es sabido que en el Islam se promulgan fatwas, es decir, dictámenes que no tienen el estatuto de Ley y cuyo objetivo es resolver algún problema práctico a los musulmanes. Una fatwa, entonces, no es una Ley, tampoco es el decreto de una autoridad estatal ni una sentencia, porque no es promulgada por un juez y carece de todo estatuto jurídico: recibe su autoridad sólo a partir del prestigio de quien la emite y que, en general, es un experto en derecho islámico (Fiqh) que la promulga a la luz de una ityihad (un esfuerzo de interpretación del Corán). Es interesante esta figura porque no corresponde ni a la universalidad de una ley sin hechos ni a la particularidad de los hechos sin una ley, sino, más bien, se presenta como la bisagra que permite una cierta orientación islámica respecto de determinados problemas. Quiero dejar en claro entonces que estos temas -el aborto y la ingeniería genética- son controvertidos para el Islam, porque sobre ellos se exhiben algunas fatwas.

\section{Aborto}

En la perspectiva del Islam, el aborto se define como la salida del embrión antes de que cumpla con los plazos propios de su desarrollo. En otras palabras, se define como la "salida del feto antes de cumplirse el embarazo". Pero este aborto puede producirse antes o después de que se le insufle el espíritu al feto. Si sucede "antes" -dicen los musulmanes- el aborto está permitido. Si sucede "después", constituye entonces un ilícito en relación con la sharia. Dice la Sura 17, 33: "No matéis a nadie que Dios haya prohibido, sino con justo motivo. Si se mata a alguien sin razón, damos autoridad a su pariente próximo pero que éste no se exceda en la venganza. Se le auxiliará".

Todo el problema reside en indicar cuándo dicho espíritu inviste al feto. Para ello, sin embargo, algunos juristas consideran un criterio teo-zoo-lógico: si el aborto se provoca antes de los 40 días de fecundación, entonces es lícito; si por el contrario se produce después de esos 40 días, es ilícito. Estos 40 días determinan biológicamente la aparición de los primeros rasgos humanos en el feto. Así, teológicamente considerado, el espíritu inviste al feto después de los 40 días, dándole características de un ser humano completo.

Es interesante que, para ciertos juristas musulmanes, el aborto es permitido antes de los 40 días, porque -dice el argumento- extraer o interrumpir el embarazo antes de los 40 días es un coitus interruptus, no un aborto. Y, según los juristas, el profeta habría permitido el coitus interruptus antes de esos 40 días.

\section{Ingeniería genética}

En general, a la ingeniería genética se la evalúa respecto de sus fines. Por ejemplo, si esta tiene por finalidad la prevención de las enfermedades, entonces, el concilio de Fiqh del sheik Abdul Qadim Zallum (¡es increíble el proceso de cristianización que ha sufrido el Islam!) se declara favorable al respecto. Pero si la ingeniería genética produce efectos nocivos para el hombre, los animales o el medio ambiente (artículo sexto), se vuelve inmediatamente ilícita. Por ello, algunas pautas promulgadas contemplan que las empresas de alimentos deben especificar los ingredientes que usan en sus productos. Asimismo, se prohíbe la utilización de la ingeniería genética para intervenir en los genes del hombre.

\section{Referencias}

1. Nancy J-L. Deconstrucción del cristianismo. Buenos Aires: La Cebra; 2006: 60.

2. Chérif M. Tolerancia e Intolerancia en el Islam. Barcelona: Bellaterra; 2008.

3. Khoury A-Th. Los fundamentos del Islam. Barcelona: Herder; 2000.

4. Taubes J. La teología Politica de Pablo. Madrid: Trotta; 2006.

5. Khoury F. Imames y Emires. Barcelona: Bellaterra; 2004.

6. Corbin H. Tiempo cíclico y gnosis ismaili. Madrid: Biblioteca Nueva; 2003.

7. Agamben G. Homo sacer. El poder soberano y la nuda vida. Valencia: Pre-textos; 2003: 238.

Recibido: 26 de abril de 2010

Aceptado: 4 de mayo de 2010 